\title{
Chemosensory Convergence on Primary Olfactory Cortex
}

\author{
Joost X. Maier, ${ }^{1}$ Matt Wachowiak, ${ }^{2}$ and Donald B. Katz ${ }^{1}$ \\ ${ }^{1}$ Volen National Center for Complex Systems, Department of Psychology, Program in Neuroscience, Brandeis University, Waltham, Massachusetts 02454, \\ and ${ }^{2}$ Department of Physiology, Brain Institute, University of Utah, Salt Lake City, Utah 84108
}

Food perception and preference formation relies on the ability to combine information from both the taste and olfactory systems. Accordingly, psychophysical investigations in humans and behavioral work in animals has shown that the taste system plays an integral role in odor processing. However, the neural basis for the influence of taste (gustation) on odor (olfaction) remains essentially unknown. Here we tested the hypothesis that gustatory influence on olfactory processing occurs at the level of primary olfactory cortex. We recorded activity from single neurons in posterior olfactory (piriform) cortex (pPC) of awake rats while presenting basic taste solutions directly to the tongue. A significant portion of pPC neurons proved to respond selectively to taste stimuli. These taste responses were significantly reduced by blockade of the gustatory epithelium, were unaffected by blockade of the olfactory epithelium, and were independent of respiration behavior. In contrast, responses to olfactory stimuli, recorded from the same area, were reduced by nasal epithelial deciliation and phase-locked to the respiration cycle. These results identify $\mathrm{pPC}$ as a likely site for gustatory influences on olfactory processing, which play an important role in food perception and preference formation.

\section{Introduction}

Our sensory experience of food, which strikes most people as unitary in nature, is actually the result of interactions between multiple sensory modalities-most notably between the taste and olfactory systems (Verhagen and Engelen, 2006). Integrating information from these two sources not only gives rise to the unique perceptual quality of flavor but also drives adaptive behavior by allowing the animal increased flexibility in forming food preferences. Despite the large body of work on food perception and preference behavior, much remains to be learned about the neural basis for taste-odor (gustatoryolfactory) interactions.

Notably understudied in this regard is the influence of the gustatory system on olfactory processing. It is clear that this influence can be powerful: the presence of a taste in mixture with an odor can enhance perceived intensity (Green et al., 2012) and detectability (Dalton et al., 2000) of that odor in humans and potentiate learned aversions to that odor in rats (Rusiniak et al., 1979; Palmerino et al., 1980). The gustatory system (Van Buskirk and Erickson, 1977; Di Lorenzo and Garcia, 1985), in particular gustatory cortex (GC), has been implicated as an important player in taste-odor interactions. Mak et al. (2005), for instance, have shown that perception of odor intensity is altered in a patient with insular lesions. Furthermore, lesions of the GC have

Received July 18, 2012; revised Sept. 14, 2012; accepted Sept. 22, 2012.

Author contributions: J.X.M., M.W., and D.B.K. designed research; J.X.M. performed research; J.X.M. analyzed data; J.X.M., M.W., and D.B.K. wrote the paper.

This work was supported by National Institutes of Health Grant DC-007703. Many thanks to Madelyn BaezSantiago and Benjamin Rubin for help with the experimental setup and Daniel Wesson for advice on implanting nasal cannulae.

The authors declare no competing financial interests.

Correspondence should be addressed to Joost X. Maier, Department of Psychology, MS 062, Brandeis University, 415 South Street, Waltham, MA 02454. E-mail: joost.maier@gmail.com.

DOI:10.1523/JNEUROSCI.3540-12.2012

Copyright $\odot 2012$ the authors $\quad 0270-6474 / 12 / 3217037-11 \$ 15.00 / 0$ been shown to affect odor-based food preference and aversion learning in rats (Inui et al., 2006; Fortis-Santiago et al., 2010).

Less work has been done to identify olfactory areas on which the gustatory system might exert influence. One possibility is that taste input affects olfactory processing via a specialized "association" area, such as the orbitofrontal cortex (Rolls and Baylis, 1994) or amygdala (Desgranges et al., 2010). However, it is also possible that the gustatory system directly influences olfactory processing at "earlier" processing levels. Given that recent work has revealed multisensory influences on primary sensory cortices (Ghazanfar et al., 2005; Lakatos et al., 2007; Iurilli et al., 2012)_including olfactory cortex (Gottfried and Dolan, 2003; Wesson and Wilson, 2010; Jadauji et al., 2012)—it is reasonable to ask whether the influence of taste on the olfactory system extends to primary cortical regions as well.

For the present study, we asked this question by probing single neurons in the posterior piriform cortex ( $\mathrm{pPC}$ ) of rats for responsiveness to basic taste stimuli. Piriform cortex is primary olfactory cortex: it receives direct odor input from the main olfactory bulb (Scott et al., 1980) and also receives extensive "crosstalk" projections from neocortical areas, including taste-related areas in agranular insular cortex (Cinelli et al., 1987; Krushel and van der Kooy, 1988; Datiche et al., 1996). Input from insular cortex is especially pronounced in the pPC (Johnson et al., 2000). This connectivity ideally situates $\mathrm{pPC}$ to play a crucial role in early integration of taste and odor signals and in mediating gustatory influences on olfactory processing. Our results show that neurons in $\mathrm{pPC}$ indeed respond to delivery of taste stimuli to the tongue.

\section{Materials and Methods}

Subjects. Methods conformed to the Brandeis University Institutional Animal Care and Use Committee guidelines. Female Long-Evans rats ( $n=19 ; 275-325 \mathrm{~g}$ at time of surgery) served as subjects in this study. Animals were maintained on a $12 \mathrm{~h}$ light/dark schedule and were given ad libitum access to chow and water, unless specified otherwise. 
Surgery. Surgical procedures were performed under ketamine/xylazine/acepromazine anesthesia $(100,5.2$, and $1 \mathrm{mg} / \mathrm{kg}$, i.p., respectively) and using a stereotaxic device for skull stabilization. Five ground screws were inserted into the skull, and a craniotomy was made through which multielectrode bundles [16 gold-plated nichrome microwires attached to a microdrive (Katz et al., 2001)] were implanted into left piriform cortex (1.4 $\mathrm{mm}$ posterior, $5.5 \mathrm{~mm}$ lateral, 5.5-7.5 mm ventral). Nasal cannulae were implanted as well, through a craniotomy into the left nasal cavity ( $0.9 \mathrm{~mm}$ lateral to the nasal fissure), and glued to the skull to create an airtight seal (Verhagen et al., 2007). Similarly, bilateral intraoral cannulae (IOC) were threaded along the skull to the oral cavity, just outside the first molar (Katz et al., 2001). Once in place, the entire assembly was cemented to the skull using dental acrylic. Rats were given $7 \mathrm{~d}$ to recover from the surgery before being subjected to experimental sessions.

Stimulus delivery. Taste stimuli used in the current study were $0.1 \mathrm{M}$ sodium chloride, $0.1 \mathrm{M}$ sucrose, $0.1 \mathrm{M}$ citric acid, and $0.001 \mathrm{M}$ quinine- $\mathrm{HCl}$ in distilled water (concentrations selected to be consistent with studies of taste responsiveness in the gustatory system; Piette et al., 2012), as well as pure distilled water rinse (three to five stimuli used per session). Tastes were delivered through IOC $(40 \mu \mathrm{l} /$ trial $)$. Water rinse $(40 \mu \mathrm{l})$ followed taste delivery by $10 \mathrm{~s}$, and tastes followed rinse by an interval of between 5 and $15 \mathrm{~s}$ (randomly selected). Stimuli were selected randomly on each trial. A session consisted of a single block of 5-20 repetitions per stimulus, depending on the animal's attentiveness.

Odor stimuli used were saturated vapors (in $\mathrm{N}_{2}$ ) of concentrated apple, cherry, and strawberry flavorants (two stimuli used per session, diluted in air; Nature's Flavors) and pure air. These complex odor stimuli were selected to maximize the likelihood of driving pPC responses (Davison and Ehlers, 2011). Odor concentration, as well as timing of odor delivery, was controlled by a custom-built olfactometer designed to deliver odorants into a clean air stream running through a nose poke (armed with an infrared detector) in an operant chamber (Verhagen et al., 2007).

To ensure odor sampling, rats were first water deprived and, in two to five adaptation sessions, trained to receive a $40 \mu \mathrm{l}$ water reward through the IOC for entering the nose poke (only clean air was presented during these sessions). During experimental sessions, odor stimuli were delivered for a duration of $2 \mathrm{~s}$, beginning when the animal's snout was within the nose poke. Odor delivery was followed by a $10 \mathrm{~s}$ refractory period, during which the nose poke was disarmed. Experimental sessions consisted of three blocks of 5-20 successful trials (trials in which rats held their nose in the nose poke for the duration of odor delivery) per odorant. Successful trials continued to be rewarded with $40 \mu$ l of water delivered via IOC $1 \mathrm{~s}$ after odor offset.

Measurement and analysis of respiration. Respiration was measured by creating an airtight connection between the nasal cannula and a pressure sensor (Honeywell 24PCAFA6G), using polyethylene tubing $(0.58 \mathrm{~mm}$ inner diameter). Pressure increases and decreases were registered as negative and positive voltage deflections, respectively, that in turn correspond to exhalations and inhalations, respectively. These signals were bandpass filtered (between 0.1 and $1000 \mathrm{~Hz}$ ), amplified (100×; Grass P55 differential amplifier; Grass Instruments), and digitized using Plexon hardware (1000 Hz sampling rate). Coherence analysis (see below) was performed on this "raw" respiration signal. Inhalation onsets (see Fig. 7B) were defined as upward zero crossings of the filtered $(0.5-20$ $\mathrm{Hz}$ ) respiration signal.

Electrophysiological recordings and data analyses. Spike waveforms (of no less than 3:1 signal-to-noise ratio) and local field potentials (LFPs) were amplified, filtered, and digitized using Plexon hardware. To obtain single-unit activity, waveforms were clustered automatically using the valley-seeking algorithm in Plexon Offline Sorter (Koontz and Fukunaga, 1972; Abolafia et al., 2011). After clustering, waveforms were visually inspected to remove clusters containing noise or artifacts. All subsequent analyses were performed in MATLAB (MathWorks). The first $100 \mathrm{~ms}$ after stimulus delivery was excluded from analysis because of transient artifacts resulting from opening and closing of valves during taste delivery.

Taste responsiveness of individual neurons was evaluated via ANOVA of average normalized ( $1000 \mathrm{~ms}$ of prestimulus activity subtracted) firing rates with factors bin (separate analyses were performed on data parsed into 10 consecutive $250 \mathrm{~ms}$ bins and three consecutive $1000 \mathrm{~ms}$ bins) and taste (all different taste stimuli, including water, delivered in that session), comparable with previous work on taste responses (Piette et al., 2012). Odor responsiveness of individual neurons was evaluated via ANOVA of average normalized (1000 ms of prestimulus activity subtracted) firing rates with factor odor (all different odorants and clean air presented in that session) and $t$ test on activity during stimulus presen- 
NEURON 1

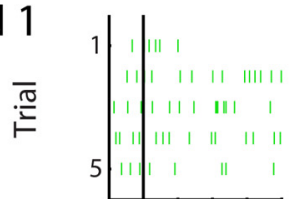

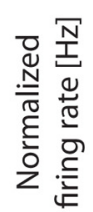

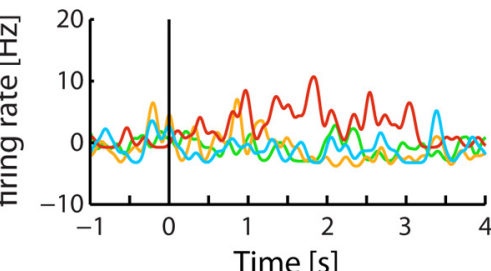

NEURON 2

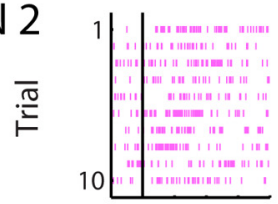

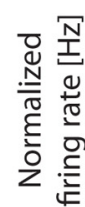

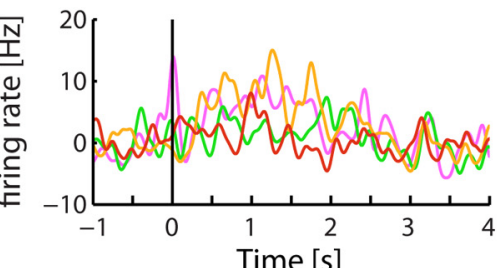

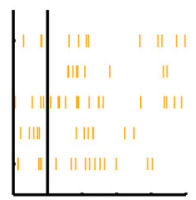
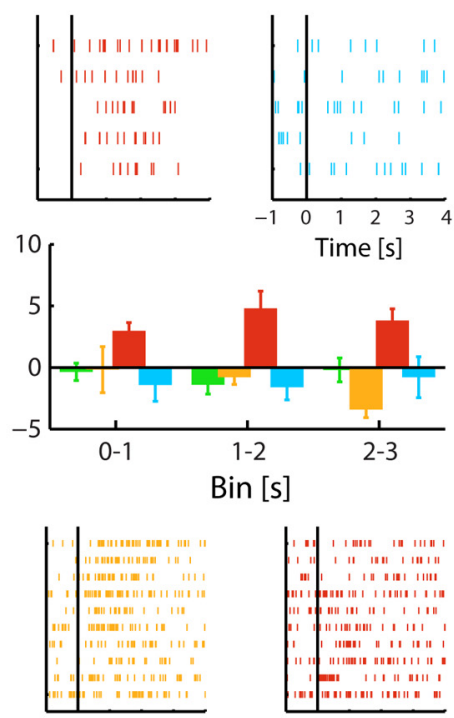

Time [s]
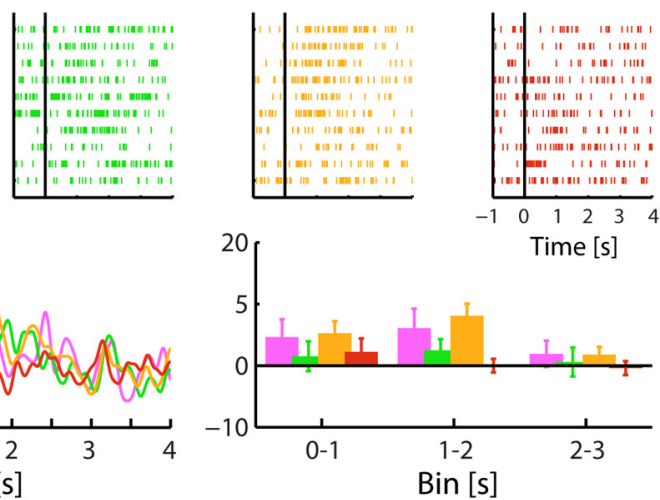

Sodium chloride

Sucrose

- Citric acid

- Quinine

Water

NEURON 3
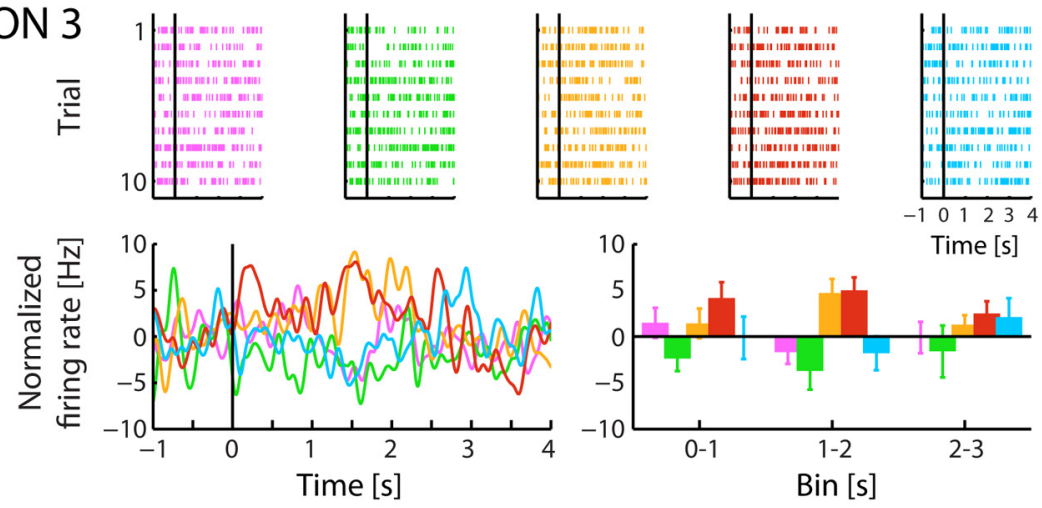

\section{NEURON 4}
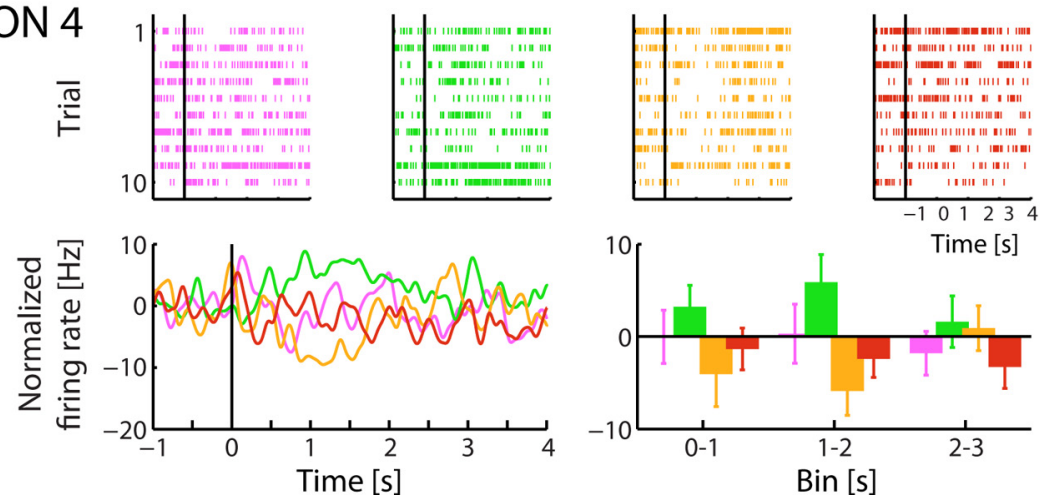

Figure 2. Taste responses in PPC. Spiking activity recorded from four example PPC neurons in response to presentation of taste stimuli. Top rows show raster plots, aligned on stimulus onset; bottom rows show averaged baseline-normalized spike density functions (aligned on stimulus onset; left columns) and averaged baseline-normalized firing rates in three consecutive $1 \mathrm{~s}$ bins after stimulus onset (right columns). All four neurons showed a significant effect of taste $\left(F_{(3,56)}=15.04, p<0.001 ; F_{(3,116)}=3.00, p=0.03 ; F_{(4,145)}=6.09, p<0.001 ; F_{(3,116)}=3.68, p=0.01\right.$, respectively). None of these four neurons showed a significant effect of bin $(F<2.49, p>0.09)$ or a significant taste $\times$ bin interaction $(F<1.09, p>0.38)$. Post hoc comparisons (Tukey-Kramer test) revealed the following significant differences: quinine versus all other responses (neuron 1); quinine versus sodium chloride and quinine versus sucrose, as well as citric acid versus sucrose (neuron 3); sucrose versus citric acid and sucrose versus quinine. 


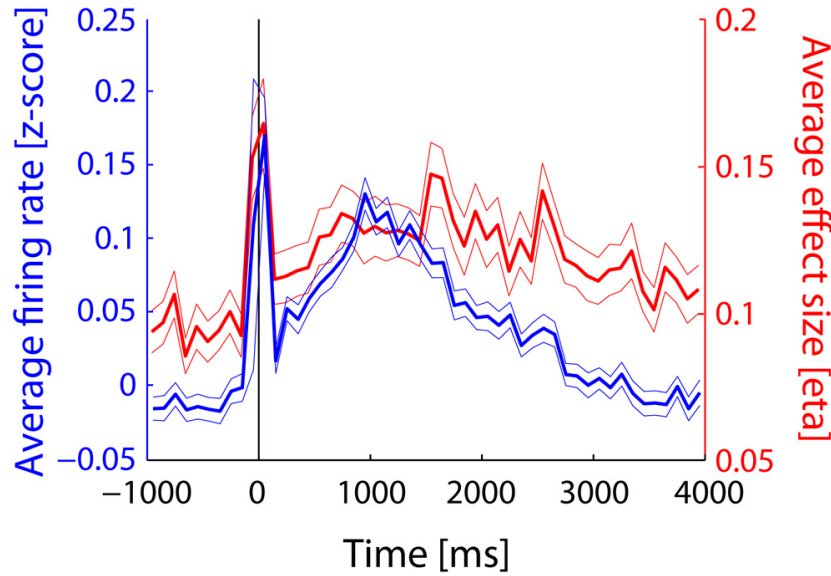

Figure 3. Population response. Average firing rate (z-score \pm SEM) and taste selectivity ( $\eta \pm$ SEM) over the population of taste-selective PPC neurons as a function of time (consecutive non-overlapping $100 \mathrm{~ms}$ bins), aligned on stimulus onset. The sharp transient peak at stimulus onset reflects the artifact caused by opening/closing of the solenoids used for taste delivery, which was excluded from all analyses presented in this paper.

Table 1. Results from two-way ANOVA of responses to tastes in pPC neurons

\begin{tabular}{lcc}
\hline Effect & \# Neurons & \% Neurons \\
\hline Taste & 112 & 51 \\
Bin & 24 & 11 \\
Interaction & 6 & 3 \\
\hline
\end{tabular}

Table 2. Breakdown of taste selectivity of pPC neurons

\begin{tabular}{lcllll}
\hline Taste & \# Responses & $\begin{array}{l}\text { \# Best } \\
\text { responses }\end{array}$ & $\begin{array}{l}\text { \% Best } \\
\text { responses }\end{array}$ & \% Excitatory & \% Inhibitory \\
\hline Sodium chloride & 86 & 20 & 23 & 30 & 70 \\
Sucrose & 109 & 18 & 17 & 44 & 56 \\
Citric acid & 110 & 41 & 37 & 63 & 37 \\
Quinine & 90 & 20 & 22 & 80 & 20 \\
Water & 94 & 13 & 14 & 24 & 77 \\
\hline
\end{tabular}

tation, averaged over all stimuli, versus baseline (1000 ms of prestimulus activity).

Coherence analysis was performed using the multitaper method implemented in Chronux routines for MATLAB. In short, coherence was calculated as the cross-spectrum between neural [continuous LFP or binned spikes ( $1 \mathrm{~ms}$ bins)] and respiration signals, normalized by the spectrum of each signal (Pesaran et al., 2002). Coherence was calculated separately for spontaneous and stimulus-induced activity. For spontaneous activity, coherence was calculated over $8 \mathrm{~s}$ preceding taste delivery. For stimulusinduced activity, coherence was calculated over $3 \mathrm{~s}$ (taste responses) or $2 \mathrm{~s}$ (odor responses) after stimulus onset and normalized by subtracting baseline coherence [ $3 \mathrm{~s}$ (taste responses) or $2 \mathrm{~s}$ (odor responses) before stimulus onset]. Shuffled data were generated by computing the coherence between neural activity in a given time period and respiration in a randomly chosen time period recorded during the same session.

Spike density functions were computed for display purposes only, by convolving each spike timestamp with a Gaussian $(S D=50$ or $5 \mathrm{~ms}$; see Fig. $7 B$ only).

Topical lingual anesthesia. In a subset of sessions, immediately after an initial recording of taste responses (5-10 trials per taste), rats were briefly anesthetized with isoflurane. Blunt tweezers were used to grasp the ventral surface of the tongue, and Anbesol, a topical oral anesthetic containing $20 \%$ benzocaine (a topical sodium channel blocker), was applied directly to the exposed dorsal surface of the tongue using a cotton swab. Isoflurane treatment was discontinued, and rats regained consciousness in $<5 \mathrm{~min}$, after which responses were recorded again (Fortis-Santiago et al., 2010).
Table 3. Breakdown of sample sizes for the different experiments

\begin{tabular}{llll}
\hline Analysis & \# Animals & \# Sessions & $\begin{array}{l}\text { \# Neurons } \\
\text { recorded }\end{array}$ \\
\hline Taste responses & 19 & 36 & 221 \\
Lingual aguesia (taste responses) & 2 & 5 & $52^{a}$ \\
Nasal epithelial deciliation (taste responses) & 5 & 5 pre; 5 post & 16 pre; 19 post \\
Locking of taste responses to respiration & 8 & 10 & 56 \\
Locking of LFP to respiration (spontaneous) & 6 & 8 & $64^{b}$ \\
Locking of spikes to respiration (spontaneous) & 8 & 10 & 56 \\
Odor responses & 4 & 6 & 45 \\
Nasal epithelial deciliation (odor responses) & 3 & 3 pre; 3 post & 13 pre; 17 post \\
Locking of odor responses to respiration & 1 & 3 & 20 \\
Multimodal responses & 4 & 6 & 41 \\
\hline
\end{tabular}

${ }^{a}$ Number of neuron-taste combinations.

${ }^{b}$ Number of LFP recording sites.

Nasal epithelial deciliation. In a separate subset of sessions, rats were anesthetized using ketamine/xylazine/acepromazine after the recording of taste and odor responses and placed in supine position. A plastic pipette tip ( $20 \mu \mathrm{l}, 15 \mathrm{~mm}$ length, $0.3 \mathrm{~mm}$ in diameter) was threaded into one nostril, and $\sim 100 \mu \mathrm{l}$ of a $0.125 \%$ Triton X-100 solution (in saline) was infused gently into the nares. After $5 \mathrm{~min}$, the infusate was withdrawn back into the pipette tip, which was then removed. Rats were then placed in a prone position for $5 \mathrm{~min}$ to allow any residual infusate to drain from the nares, and the infusion procedure was repeated on the other nostril (Fortis-Santiago et al., 2010). This procedure has been shown to render rats functionally anosmic for a period of $72 \mathrm{~h}$ (Fortis-Santiago et al., 2010, M.W., unpublished observation), presumably by dissolving the cilia on olfactory receptor neurons, which are then replaced via neurogenesis (Nadi et al., 1981; Mair et al., 1982; Vassar et al., 1994). Therefore, when responses were again recorded $24 \mathrm{~h}$ after treatment, they were recorded under a condition of relative olfactory compromise.

Confirmation of recording sites. After experimental sessions, subjects were deeply anesthetized and perfused through the heart with saline, followed by $10 \%$ Formalin. Ten seconds of direct current $(5-10 \mu \mathrm{A})$ were passed through the electrodes from which taste-selective neurons were recorded to lesion recording sites. Brains were removed and kept immersed in a $30 \%$ sucrose $/ 10 \%$ Formalin mixture until completely fixed. Once fixed, coronal sections ( $80 \mu \mathrm{m}$ thick) were cut using a freezing microtome and stained with cresyl violet to visualize cell bodies. Figure $1 A$ shows an example brain slice, revealing the location of three electrodes in pPC. Figure $1 B$ shows a schematic indicating the location of reconstructed recording sites that showed significant taste-selective responses obtained from six animals. Recording sites were confined to piriform cortex, sparing nonprimary olfactory structures that could potentially also contain neurons with gustatory responses, such as the endopiriform cortex (Fu et al., 2004; Sugai et al., 2005). Confirmation of recording location was further established by showing that both spontaneous LFP and spiking activity was modulated by the respiration cycle (data not shown). Coherence analysis between respiration and both LFP and spiking activity revealed a peak in the spectrum at frequencies between 1 and $10 \mathrm{~Hz}$ (relative to shuffled data). This frequency band coincided with the range of respiration frequencies displayed by the animal, strengthening our conclusion that electrode tips were indeed buried in the olfactory system.

\section{Results}

\section{Piriform cortex responds to tastes}

Across a sample of 19 awake rats, we recorded spiking activity from a total of $221 \mathrm{pPC}$ neurons in response to intraoral presentation of a subset of basic taste solutions (sodium chloride, sucrose, citric acid, and quinine) and distilled water. Many of these neurons responded to taste administration. Figure 2 shows canonical raster plots and peristimulus time histograms produced from example pPC neurons (more examples are shown in Figs. $4 A, 8 B$ ), which showed significant taste responses. As can be seen from Figure 2, neurons responded in a more or less selective 
A
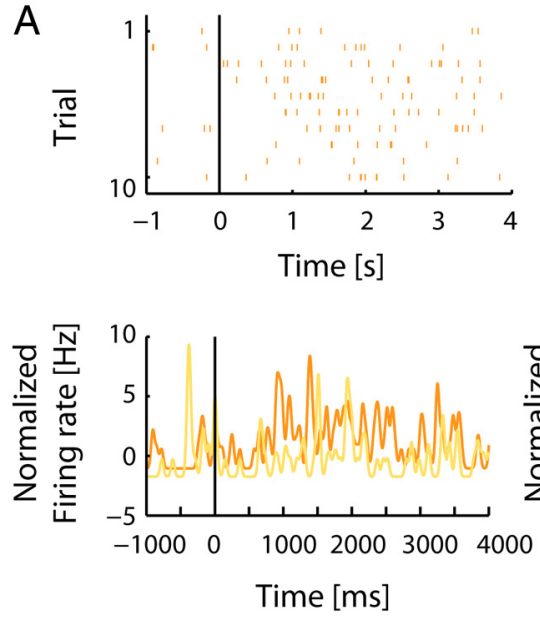

B
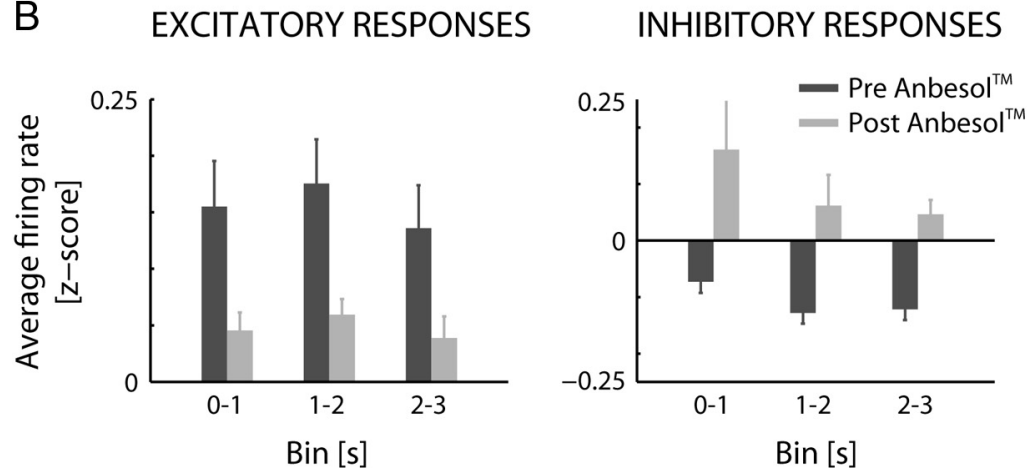

Figure 4. Effect of blocking gustatory afferents. $A$, Example of a $\mathrm{pPC}$ neuron responding to citric acid, before and after application of Anbesol to the tongue. Top row shows raster plots, aligned on stimulus onset; bottom row shows averaged baselinenormalized spike density functions, aligned on stimulus onset (left column) and averaged baseline-normalized firing rates in three consecutive $1 \mathrm{~s}$ bins after stimulus onset (right column). Responses to citric acid were significantly reduced by application of Anbesol. B, Averaged firing rates (z-score) before and after Anbesol over the population of significant neuron-taste pairs, separate for excitatory (left) and inhibitory (right) responses.

manner, some responding to only one stimulus (Fig. 2A) and some responding distinctly to presentation of several taste stimuli (Fig. 2B-D). These examples also reveal the diversity of stimuli causing the strongest responses: quinine caused the strongest response in the neuron shown in Figure 2A; sucrose caused the strongest response in the neuron shown in Figure $2 D$; the neuron shown in Figure $2 B$ responds to citric acid and sodium chloride; and the neuron shown in Figure $2 C$ responds to citric acid and quinine.

Responses were subjected to two-way ANOVA with factors taste and bin. Main effects of taste indicate taste-specific responses, main effects of bin indicate nonspecific responses, and taste $\times$ bin interactions indicate taste-specific time courses of response. Using conservative criteria used previously to characterize taste responsiveness (10 consecutive $250 \mathrm{~ms}$ bins, $\alpha=$ 0.001; Piette et al., 2012), approximately half of the pPC neurons ( $n=109,49 \%$ ) modulated their firing rate in response to delivery of taste stimuli: $101(46 \%)$ showed significant main effects of taste, $21(10 \%)$ showed significant main effects of bin, and only three $(1 \%)$ showed significant taste $\times$ bin interactions. Figure 3 plots effect sizes for taste, as well as normalized firing rates, averaged over all taste-selective neurons in consecutive nonoverlapping $100 \mathrm{~ms}$ bins. Firing rates slowly increased after stimulus onset, peaking at $\sim 1 \mathrm{~s}$ after stimulus; stimulus selectivity followed a similar time course. For both measures, there was large between-neuron variability, such that the average onset of taste selectivity (defined as the first consecutive non-overlapping $100 \mathrm{~ms}$ bin after stimulus onset that showed a significant effect of taste according to one-way ANOVA) was $829 \pm 70 \mathrm{~ms}$ (mean $\pm \mathrm{SE}$ ). Given this slow time courses of taste responses, we will analyze taste responses using three consecutive $1 \mathrm{~s}$ bins for the remainder of this manuscript (Table 1 ). The use of fixed concentrations could have contributed to the overall slow onset of taste responses as well as to the large between-neuron variability, because the concentrations used for the different tastes in the present study may differentially recruit input pathways to pPC (see Discussion).

Across the population, there was a diversity of responses to different tastes or combinations of tastes in pPC neurons: best responses (the taste that evoked the largest modulation in firing rate for a given neuron) were more often observed to unpalatable tastes (i.e., unpleasant tastes, such as citric acid and quinine) than to palatable tastes (i.e., pleasant tastes, such as sodium chloride and sucrose; $\left.X_{(1)}^{2}=6.38, p=0.01\right)$. Water, a palatable taste, was excluded from this analysis (as well as from the analysis described immediately below). Including responses to water, however, did not change the results (Table 2). Although unpalatable tastes evoked more best responses, it is important to note that every taste was the best stimulus for at least some neurons (for examples, see Fig. 2; for taste-to-taste breakdown of responses, see Table 2 ). This taste selectivity could emerge from either excitatory or inhibitory responses (for examples, see Fig. 2): 59 taste-selective neurons (53\%) increased their firing rate in response to taste stimuli, and 53 neurons (48\%) decreased their firing rate. Excitatory responses were most often strongest for unpalatable tastes: $63 \%$ of citric acid-best and $80 \%$ of quinine-best responses were excitatory versus $30 \%$ of sodium chloride-best and $44 \%$ of sucrose-best responses $\left(X_{(1)}^{2}=9.77\right.$, $p<0.01$; Table 2).

\section{pPC taste responses are of gustatory origin}

Taste solutions contain volatile components (Miller and Erickson, 1966; Smith and Theodore, 1984; Rhinehart-Doty et al., 1994; Capaldi et al., 2004; Zukerman et al., 2009), and intraoral delivery of these solutions may stimulate olfactory receptors retronasally (Gautam and Verhagen, 2012). Thus, although the data presented above demonstrate that single neurons in $\mathrm{PPC}$ respond selectively to delivery of basic taste stimuli, it is reasonable to ask whether these responses are truly of gustatory (as opposed to olfactory) origin, that is, whether they are the result of transduction of the lingual or nasal epithelium.

We addressed this question in three different experiments, which together confirm that gustatory stimulation is necessary and sufficient to produce the responses described above. First, we performed a set of experiments in which we recorded responses from single $\mathrm{pPC}$ neurons to taste stimuli (Table 3), before and after temporarily in- 


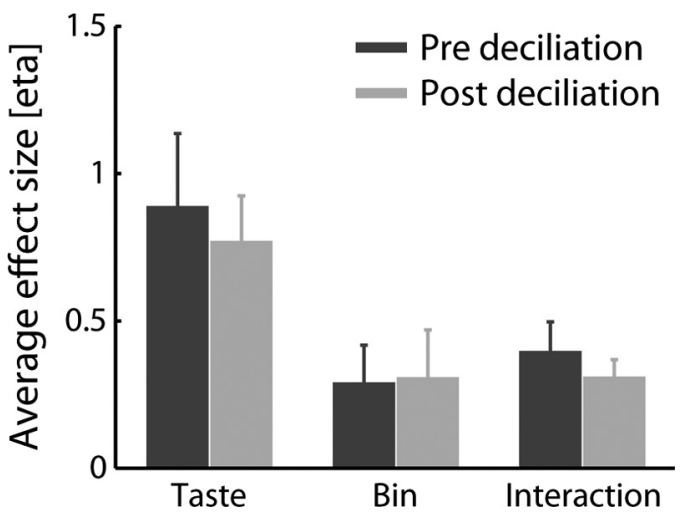

Figure 5. Effect of nasal epithelial deciliation. Average effect size $(\eta)$ obtained from twoway ANOVA over the population of $\mathrm{PCC}$ neurons, before and after nasal epithelial deciliation. Deciliation did not affect taste responses.
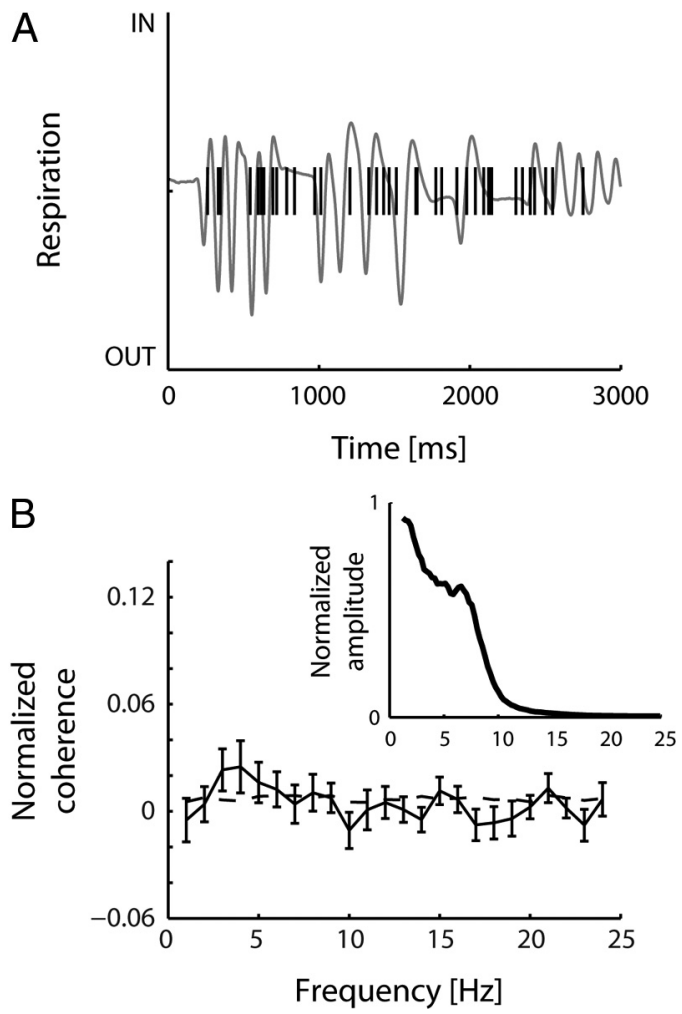

Figure 6. Modulation of taste responses by respiration. $\boldsymbol{A}$, Filtered respiration and spikes (vertical lines) during a single trial (first $3000 \mathrm{~ms}$ after taste onset). $\boldsymbol{B}$, Average baselinenormalized coherence between respiration and spiking responses of the population of tasteselective $\mathrm{pPC}$ neurons, as a function of frequency (solid line). Dashed line shows coherence obtained from shuffled data. Inset shows the average respiration spectrum obtained from the sessions used for this analysis.

activating gustatory afferents by applying Anbesol (a topical anesthetic designed specifically for oral use) directly to the tongue. We have shown previously that this preparation greatly reduces the evidence of taste responses in GC without impacting odor recognition (Fortis-Santiago et al., 2010). Therefore, we expected that, if pPC responses to taste stimuli are of gustatory origin, they should be similarly reduced after Anbesol application. Conversely, if the responses are of olfactory origin, we expected that they should be unaffected by inactivation of the tongue.

The results of this experiment are presented in Figure 4. Figure $4 A$ shows the response of an example pPC neuron to citric acid.
Before application of Anbesol to the tongue, this neuron responded to citric acid with an increase in firing rate. After application of Anbesol, this response was significantly reduced and in fact not different from spontaneous, prestimulus firing. Analysis of all neuron-taste combinations in this sample that showed a significant excitatory or inhibitory response $(n=15,29 \%$; as determined by $t$ test on the average normalized firing rate $1 \mathrm{~s}$ before stimulus vs $3 \mathrm{~s}$ after stimulus) revealed that lingual inactivation significantly reduced both excitatory and inhibitory responses (Fig. 4B). Any apparent above-baseline post-Anbesol firing in inhibited neurons is actually not significant. Two-way repeated-measures ANOVAs with factors epoch (before and after application of Anbesol) and bin, performed on the averaged normalized responses across all tastes, revealed a significant effect of epoch for both excitatory $\left(F_{(1,35)}=8.81, p=0.01\right)$ and inhibitory $\left(F_{(1,35)}=7.09, p<0.05\right)$ responses. Similar effects were observed when each taste was analyzed individually. These experiments demonstrate that the magnitude of pPC responses to taste stimuli was reduced or outright eliminated after blocking gustatory afferents with Anbesol, suggesting that taste responses in pPC are, at least partly, of gustatory origin (for consideration of trigeminal pathways, see Discussion).

We next performed the approximate converse experiment, recording responses to taste stimuli before and after deciliation of the nasal epithelium via application of $0.125 \%$ Triton X-100 (in saline) to the nasal cavity in a subset of animals (Table 3). Previous work has shown that this procedure impairs the processing of olfactory stimuli for 3-4 d (Fortis-Santiago et al., 2010, M.W., unpublished observation). Therefore, we predicted that, if pPC responses to taste stimuli are of gustatory origin, they would be essentially unaffected after nasal deciliation. Because it was not possible to record responses before and after deciliation on the same day and because we could not reliably maintain isolation of the same neurons across multiple days, we compared taste selectivity from separate samples of pPC neurons recorded from the same cortical locations, just before and $1 \mathrm{~d}$ after deciliation.

Figure 5 shows the average effects sizes for $\mathrm{pPC}$ taste responses (obtained from ANOVA with factors taste and bin), before and after deciliation. Two-way ANOVA comparing pre-deciliation and post-deciliation effect size [factors epoch (pre and post) and factor (taste, bin, interaction)] showed no significant effect of epoch $\left(F_{(1,104)}=0.28, p>0.59\right)$. Although we cannot definitively conclude that temporary lesions of the nasal epithelium had absolutely no impact on taste responsiveness in pPC, the selectivity of taste-evoked responses was not significantly diminished by the procedure.

Finally, we recorded $\mathrm{pPC}$ responses to tastes while monitoring respiration (via intranasal cannula) in a subset of animals (Table 3 ). It has been shown repeatedly that primary (orthonasal) olfactory responses are modulated as a function of respiration (Macrides and Chorover, 1972; Ogawa, 1998; Kay and Laurent, 1999; Buonviso et al., 2006; Rennaker et al., 2007; Cury and Uchida, 2010; Carey and Wachowiak, 2011; Shusterman et al., 2011; Miura et al., 2012). Although it is not yet known whether and how retronasal olfactory responses are modulated by respiration, retronasal olfactory stimulation likely relies on airflow produced by expiration (Masaoka et al., 2010). Therefore, if pPC responses to tastes are the result of olfactory stimulation, we expect these responses to be similarly modulated by the animals' respiration (see below). Figure $6 A$ shows respiration and spiking activity recorded during a single presentation of sodium chloride to the tongue. Spiking activity does not have any obvious relationship to the respiration phase. We used coherence as a measure to quantify 
A
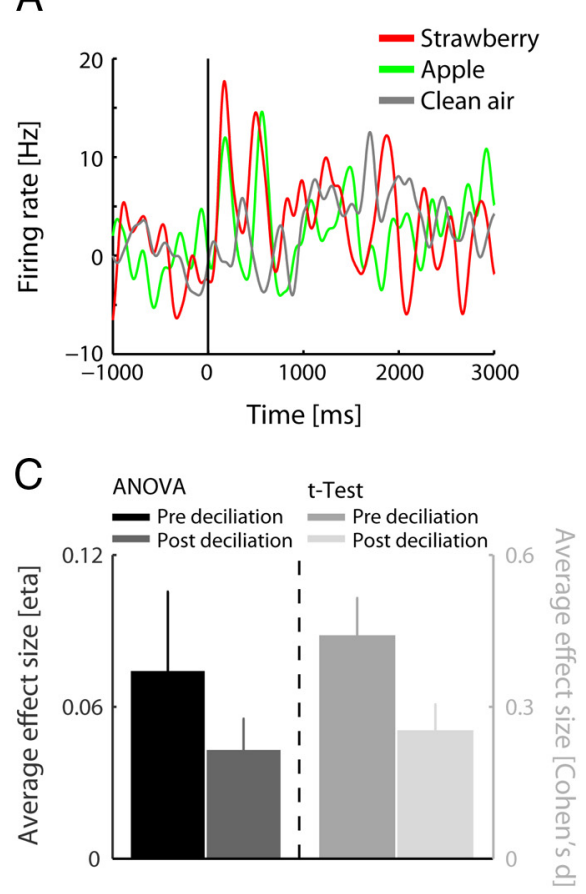

B

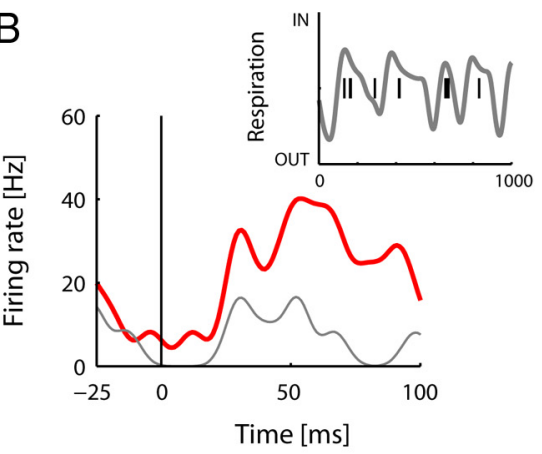

D

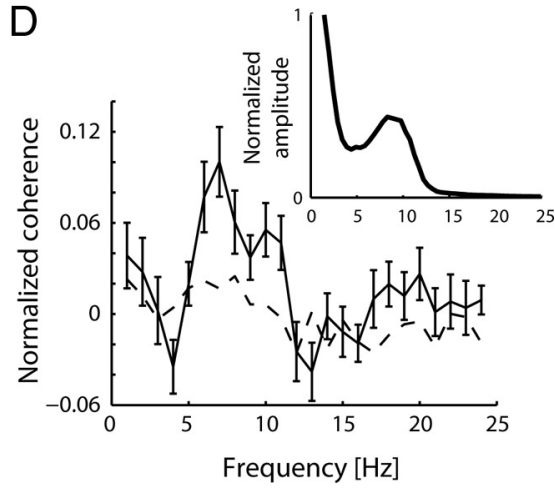

Figure 7. Odor responses in PPC. A, Baseline-normalized spiking activity of an example pPC neuron in response to odor stimuli, aligned on stimulus onset. $\boldsymbol{B}$, Responses to strawberry odor and clean air (same neuron as shown in $\boldsymbol{A}$ ), aligned on first inhalation onset. Inset shows filtered respiration and spikes (vertical lines) during a single trial (first $100 \mathrm{~ms}$ after odor onset). $\boldsymbol{C}$, Average effect size obtained from ANOVA $(\eta)$ and $t$ test (Cohen's $d$ ) over the population of pPC neurons, before and after nasal epithelial deciliation. Odor responses were significantly reduced after deciliation. $\boldsymbol{D}$, Average baseline-normalized coherence between respiration and spiking responses of the population of odor-responsive $\mathrm{pPC}$ neurons, as a function of frequency (solid line). Dashed line shows coherence obtained from shuffled data. Inset shows the average respiration spectrum obtained from the sessions used for this analysis.

the relationship between spiking activity and respiration phase. Figure $6 B$ plots the average stimulus-induced coherence between taste-induced spiking activity and respiration as a function of frequency (for details, see Materials and Methods), for all neurons that showed a significant effect of taste $(n=25,45 \%)$. The spectrum shows no significant peaks relative to shuffled data (compare with Fig. $7 B$ ). The inset shows the respiration spectrum used for calculating the coherence.

Together, data from these three experiments suggest that pPC responses to taste stimuli are genuine taste responses and not the result of olfactory stimulation.

\section{Piriform cortex responds to odors}

In an additional set of experiments, we recorded pPC responses to odor stimuli from a total of 45 neurons from a subset of animals (Table 3 ), directly demonstrating the involvement of the region in olfactory processing. Odor stimuli were complex mixtures of odorants (cherry, apple, strawberry) and clean air, presented orthonasally for $2 \mathrm{~s} /$ trial after triggering of a nose poke by the animal. Normalized firing rates during the stimulus period were subjected to $t$ test to determine odor responsiveness and to one-way ANOVA (factor odor) to determine odor selectivity. A total of 34 neurons $(76 \%)$ responded to odor sampling, and, despite the limited stimulus space (only two different odor stimuli were presented in each recording session), 15 neurons (33\%) showed odor-selective responses.

Figure $7 A$ shows the activity of an example pPC neuron aligned on odor onset, demonstrating a significant response to odor sam-

pling. Figure $7 B$ shows the response of the same neuron to strawberry odor, aligned on first inhalation onset, demonstrating a stimulus-specific, inhalation-driven response (Miura et al., 2012). Two additional tests make us confident that these odor responses are truly olfactory. First, experiments on a subset of animals (Table 3) showed that nasal epithelial deciliation, which had no impact on responses to tastes (see above), significantly reduced recorded odorant responses (Fig. 7C): a two-way ANOVA with factors epoch (pre, post) and test ( $t$ test, ANOVA) on effect size measurements revealed a significant effect of epoch $\left(F_{(1,59)}=6.31, p=0.01\right)$. Furthermore, odor-responsive neurons $(n=15,75 \%$, as determined by $t$ test or ANOVA on averaged activity during the odor stimulus period) showed a significant peak in stimulusinduced coherence with respiration compared with shuffled data (Fig. $7 D$, compare with Fig. 6, which shows lack of coherence between respiration and taste responses).

These data suggest that neurons in our recording location indeed received and responded to olfactory stimulation. Thus, our results show that our recordings exhibit functional characteristics of olfactory neurons. Together with anatomical data, they strongly suggest that recordings were indeed made from pPC and that the taste responses of these neurons represent independently generated, convergent input on these neurons.

\section{Odors and tastes activate overlapping subsets of neurons in $\mathrm{pPC}$}

To confirm that individual pPC neurons indeed receive converging gustatory and olfactory input, we recorded responses to both taste and odor stimuli from a total of 41 neurons. Of these neurons, $13(32 \%)$ responded to odors only (significant effect of $t$ test or ANOVA), nine (22\%) responded to tastes only (two-way ANOVA, significant effect of taste), and seven (17\%) corresponded to both odors and tastes. Figure 8 shows two neurons that respond to both odor and taste stimuli. For example, the neuron on the left in Figure $8 \mathrm{~A}$ responded strongly but differentially to apple and cherry odor but not to clean air. In Figure $8 B$, this same neuron is shown to respond selectively to unpalatable taste solutions. Figure 8, $C$ and $D$, shows the stability of the spike waveforms and interspike intervals for these two units across odor and taste recording sessions.

Thus, pPC receives both gustatory and olfactory input, and convergence of gustatory and olfactory input takes place in single pPC neurons.

\section{Discussion}

In the present study, we probed single neurons in the primary olfactory cortex of the rat for responsiveness to basic tastes. We found that a substantial number of neurons in pPC respond selectively to presentation of taste solutions to the tongue. This suggests that olfactory cortex is a node in the network mediating chemosensory integration. Multisensory interactions have tradi- 
tionally been thought of as taking place in specialized multisensory brain areas (Stein and Meredith, 1993). However, our finding that primary olfactory cortex receives gustatory input is in line with a growing body of evidence from other sensory systems, showing that all primary sensory cortices-previously thought of as unimodal-also receive heteromodal sensory input (Ghazanfar et al., 2005; Lakatos et al., 2007; Kayser et al., 2008; Wesson and Wilson, 2010; Cohen et al., 2011; Iurilli et al., 2012) and are involved in multisensory integration.

Our decision to focus on pPC was made on the basis of anatomical considerations. Although both the anterior and posterior portions of the olfactory cortex receive direct input from mitral cells in the olfactory bulb (Scott et al., 1980), the contribution of direct olfactory input relative to intracortical "association" projections is smaller in pPC (Haberly and Price, 1978; Luskin and Price, 1983; Shi and Cassell, 1998; Johnson et al., 2000). Our findings confirm the role of $\mathrm{pPC}$ as both a primary olfactory area and an association area within the olfactory system (Haberly, 2001; Wilson and Sullivan, 2011), combining olfactory input with gustatory input.

Several findings indicate that the observed responses to taste stimuli in pPC indeed originate from the gustatory system and are not the result of input from other sensory or neuromodulatory systems. First, lack of taste response in aguesic animals and the fact that taste responses are not modulated by respiration indicate that responses are not of olfactory origin. Second, the observed taste selectivity of responses are unlikely to have been caused by somatosensory input or input from modulatory pathways involved in arousal or signaling of aversive stimuli: somatosensory input would yield either nonspecific responses (Katz et al., 2001) or purely palatability-related responses appearing more than $1 \mathrm{~s}$ after stimulus (Travers and Norgren, 1986), as would modulatory input. These predictions are inconsistent with the specific and varied responses observed in pPC (Fig. 2).

The existence of a network consisting of primary gustatory and olfactory areas suggests that chemosensory interactions may be mediated through direct communication between sensory systems (Driver and Noesselt, 2008; Maier et al., 2008). That is, crossmodal integration occurs through interactions between primary sensory systems without first converging onto specialized multisensory areas. However, differences in the anatomical patterns of heteromodal convergence between piriform cortex and neocortical areas suggest that the cellular mechanisms of crossmodal interactions are different.
NEURON 1
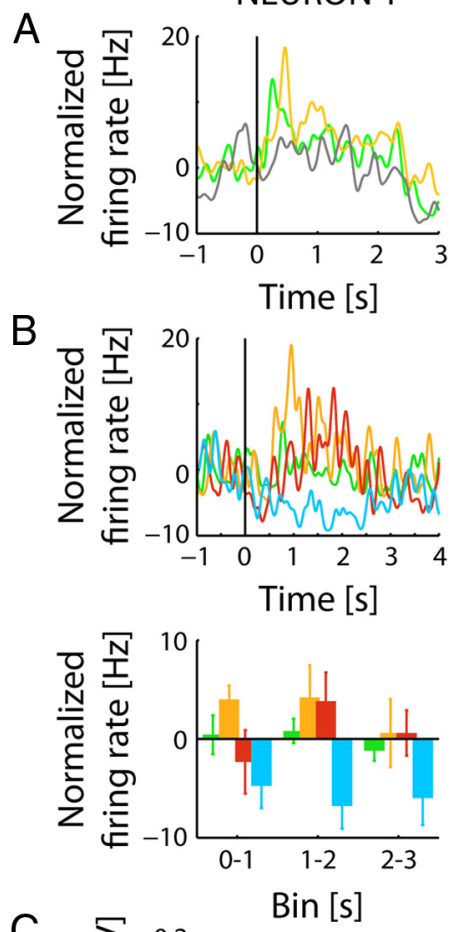

$\mathrm{D}$

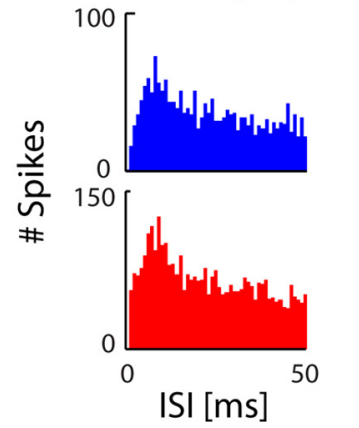

NEURON 2
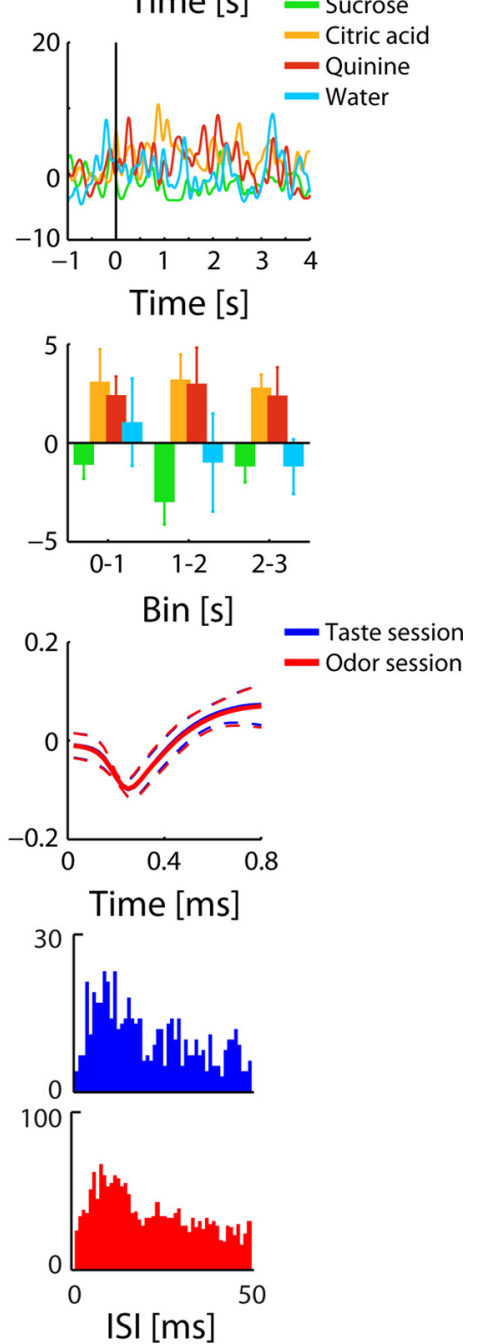

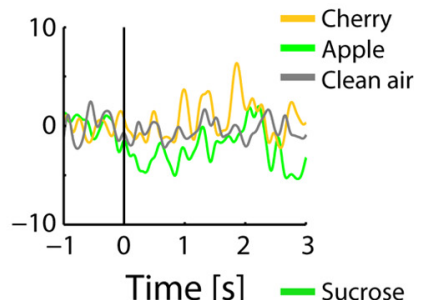

Figure 8. Taste and odor responses in single pPC neurons. $\boldsymbol{A}$, Baseline-normalized spike density functions in response to odor stimuli, aligned on stimulus onset. Both neurons showed a significant effect of odor $\left(F_{(2,41)}=3.67, p=0.03 ; F_{(2,41)}=3.49, p=\right.$ 0.04 , respectively). Post hoc comparisons (Tukey-Kramer test) revealed the following significant differences: apple versus cherry (neuron 1); cherry versus air (neuron 2). B, Baseline-normalized spike density function in response to taste stimuli, aligned on stimulus onset (top row) and baseline-normalized firing rate in response to taste stimuli in three consecutive $1 \mathrm{~s}$ bins after stimulus onset (bottom row). Both neurons showed a significant effect of taste $\left(F_{(3,56)}=6.90, p<0.001 ; F_{(3,56)}=7.33, p<0.001\right.$, respectively). None of these two neurons showed a significant effect of bin $(F<0.66, p>0.52)$ or a significant taste $\times$ bin interaction ( $F<0.54, p>0.70$ ). Post hoc comparisons (Tukey-Kramer test) revealed the following significant differences: water versus all other responses (neuron 1); sucrose versus citric acid and sucrose versus quinine, as well as citric acid versus water (neuron 2). C, Average \pm SEM waveforms of the action potentials isolated during taste and odor sessions. $\boldsymbol{D}$, Inter-spike intervals (ISI) of the units isolated during taste and odor sessions.

In sensory neocortex, heteromodal feedback projections often terminate in a particular pattern (i.e., specifically projecting to infragranular and supragranular layers) (Schroeder and Foxe, 2002; Lakatos et al., 2007), influencing pyramidal cells by activating local inhibitory circuits (Iurilli et al., 2012). In contrast, principal cells in piriform cortex receive direct converging olfactory input from the olfactory bulb and heteromodal input from cor- 
tical and subcortical areas (Schoenbaum and Eichenbaum, 1995; Haberly, 2001).

One possible source of taste input to piriform cortex is the primary GC in the insula (Cinelli et al., 1987; Krushel and van der Kooy, 1988; Datiche et al., 1996). Imaging studies in humans have implicated GC in flavor perception (Veldhuizen et al., 2010), that is, in combining taste and odor signals. Furthermore, loss of GC has been shown to impair odor intensity ratings in humans (Mak et al., 2005) and performance on odor learning tasks in rats (Inui et al., 2006; Fortis-Santiago et al., 2010). However, gustatory information may also reach pPC via gustatory cells in the basolateral nucleus of the amygdala (BLA). Functional interactions between the BLA and GC play an important role in taste palatability processing (Piette et al., 2012). In fact, dynamics of taste responses in pPC are more similar to taste responses in the BLA than to taste responses in GC. Taste responses in GC usually exhibit an early (0-250 ms) nonspecific component that gives way to taste-specific activity later and palatability-specific activity later still: ANOVA of such response patterns typically yields main effects of bin and/or taste $\times$ bin interaction effects (Katz et al., 2001). Conversely, taste responses in BLA reflect palatability and emerge slowly. This response pattern yields predominantly main effects of taste (Fontanini et al., 2009; present study), similar to what we observe in the present study. Thus, amygdalar feedback may well be the driving force behind our observed taste responses.

Of course, it is also possible that gustatory and olfactory input first converge onto dedicated multisensory areas, which in turn influence primary sensory processing in pPC. Such a mechanism has been proposed for auditory-visual interactions in auditory cortex, in which visual input reaches auditory cortex after a feedback pattern (Schroeder and Foxe, 2002), possibly originating from multisensory areas (Ghazanfar et al., 2005; McDonald et al., 2005; Noesselt et al., 2007). Both the amygdala and orbitofrontal cortex are anatomically connected to the piriform cortex (Haberly and Price, 1978; Luskin and Price, 1983; Johnson et al., 2000) and are thought to be nodes in the chemosensory "flavor network." The amygdala has been shown previously to receive converging gustatory and olfactory input during flavor preference learning (Desgranges et al., 2010). Electrophysiological recordings in nonhuman primates (Rolls and Baylis, 1994) and imaging studies in humans (de Araujo et al., 2003; Small et al., 2004) have shown chemosensory interactions in the orbitofrontal cortex, which have also been linked to flavor perception. Thus, multisensory populations in amygdala and/or orbitofrontal cortex could indirectly modulate neural activity in olfactory cortex after gustatory stimulation.

The idea that olfactory cortex is involved in chemosensory integration leaves unanswered the question what its role is in the "flavor network." Behavioral work has shown that the gustatory system plays an integral role in odor perception (Mak et al., 2005; Inui et al., 2006; Fortis-Santiago et al., 2010). For example, a recent study on the social transmission of food preference paradigm showed that chemical inactivation of GC influences odorbased food preference learning in a state-dependent manner: olfactory memory formed while GC was inactivated was only be successfully recalled when GC was inactivated again during recall (Fortis-Santiago et al., 2010). Our data implicate pPC as a possible neural substrate for mediating this influence. Future work aimed at unraveling circuit-level processing in the flavor network will elucidate the mechanisms by which the gustatory system may influence olfactory processing in $\mathrm{pPC}$.
Another question that arises is how combined gustatoryolfactory inputs are integrated. Previous work on multisensory integration has stressed the importance of the temporal relationship between bimodal inputs (Meredith et al., 1987; Maier et al., 2011). During natural feeding behavior, odor signals reach the olfactory system via two distinct routes (Rozin, 1982; Gautam and Verhagen, 2012): Orthonasally (i.e., through the nostrils) and retronsally (i.e., via the mouth, during consumption). Both orthonasal and retronasal olfactory stimulation activate the piriform cortex in humans (Small et al., 2005), and both are integrated with gustatory input during flavor perception and preference learning (Chapuis et al., 2007). However, the two types of stimulation have a different temporal relationship to gustatory stimulation. Before consumption, odor signals emanating from a food source reach the animal orthonasally. In this situation, olfactory stimulation precedes gustatory stimulation, which occurs during consumption. Although the exact temporal dynamics of retronasal olfactory stimulation is to date unknown, it occurs during consumption and may therefore follow, or be temporally synchronous, with gustatory stimulation. These different temporal profiles of olfactory-gustatory input imply different mechanisms of chemosensory integration at the network and cellular level, operating with different temporal constraints.

In summary, we have identified posterior olfactory cortex as a node in the network involved in chemosensory integration. This finding opens up exciting new possibilities for additional research into the multimodal nature of sensory processing and the question of how multisensory interactions in the flavor network mediate adaptive behavior.

\section{References}

Abolafia JM, Martinez-Garcia M, Deco G, Sanchez-Vives MV (2011) Slow modulation of ongoing discharge in the auditory cortex during an interval-discrimination task. Front Integr Neurosci 5:60. CrossRef Medline

Buonviso N, Amat C, Litaudon P (2006) Respiratory modulation of olfactory neurons in the rodent brain. Chem Senses 31:145-154. CrossRef Medline

Capaldi ED, Hunter MJ, Privitera GJ (2004) Odor of taste stimuli in conditioned "taste" aversion learning. Behav Neurosci 118:1400-1408. CrossRef Medline

Carey RM, Wachowiak M (2011) Effect of sniffing on the temporal structure of mitral/tufted cell output from the olfactory bulb. J Neurosci 31: 10615-10626. CrossRef Medline

Chapuis J, Messaoudi B, Ferreira G, Ravel N (2007) Importance of retronasal and orthonasal olfaction for odor aversion memory in rats. Behav Neurosci 121:1383-1392. CrossRef Medline

Cinelli AR, Ferreyra-Moyano H, Barragan E (1987) Reciprocal functional connections of the olfactory bulbs and other olfactory related areas with the prefrontal cortex. Brain Res Bull 19:651-661. CrossRef Medline

Cohen L, Rothschild G, Mizrahi A (2011) Multisensory integration of natural odors and sounds in the auditory cortex. Neuron 72:357-369. CrossRef Medline

Cury KM, Uchida N (2010) Robust odor coding via inhalation-coupled transient activity in the mammalian olfactory bulb. Neuron 68:570-585. CrossRef Medline

Dalton P, Doolittle N, Nagata H, Breslin PA (2000) The merging of the senses: integration of subthreshold taste and smell. Nat Neurosci 3:431432. CrossRef Medline

Datiche F, Litaudon P, Cattarelli M (1996) Intrinsic association fiber system of the piriform cortex: a quantitative study based on a cholera toxin B subunit tracing in the rat. J Comp Neurol 376:265-277. CrossRef Medline

Davison IG, Ehlers MD (2011) Neural circuit mechanisms for pattern detection and feature combination in olfactory cortex. Neuron 70:82-94. CrossRef Medline

de Araujo IE, Rolls ET, Kringelbach ML, McGlone F, Phillips N (2003) Taste-olfactory convergence, and the representation of the pleasantness 
of flavour, in the human brain. Eur J Neurosci 18:2059-2068. CrossRef Medline

Desgranges B, Ramirez-Amaya V, Ricaño-Cornejo I, Lévy F, Ferreira G (2010) Flavor preference learning increases olfactory and gustatory convergence onto single neurons in the basolateral amygdala but not in the insular cortex in rats. PLoS One 5:e10097. CrossRef Medline

Di Lorenzo PM, Garcia J (1985) Olfactory responses in the gustatory area of the parabrachial pons. Brain Res Bull 15:673-676. CrossRef Medline

Driver J, Noesselt T (2008) Multisensory interplay reveals crossmodal influences on "sensory-specific" brain regions, neural responses, and judgments. Neuron 57:11-23. CrossRef Medline

Fontanini A, Grossman SE, Figueroa JA, Katz DB (2009) Distinct subtypes of basolateral amygdala taste neurons reflect palatability and reward. J Neurosci 29:2486-2495. CrossRef Medline

Fortis-Santiago Y, Rodwin BA, Neseliler S, Piette CE, Katz DB (2010) State dependence of olfactory perception as a function of taste cortical inactivation. Nat Neurosci 13:158-159. CrossRef Medline

Fu W, Sugai T, Yoshimura H, Onoda N (2004) Convergence of olfactory and gustatory connections onto the endopiriform nucleus in the rat. Neuroscience 126:1033-1041. CrossRef Medline

Gautam SH, Verhagen JV (2012) Retronasal odor representations in the dorsal olfactory bulb of rats. J Neurosci 32:7949-7959. CrossRef Medline

Ghazanfar AA, Maier JX, Hoffman KL, Logothetis NK (2005) Multisensory integration of dynamic faces and voices in rhesus monkey auditory cortex. J Neurosci 25:5004-5012. CrossRef Medline

Gottfried JA, Dolan RJ (2003) The nose smells what the eye sees: crossmodal visual facilitation of human olfactory perception. Neuron 39:375-386. CrossRef Medline

Green BG, Nachtigal D, Hammond S, Lim J (2012) Enhancement of retronasal odors by taste. Chem Senses 37:77-86. CrossRef Medline

Haberly LB (2001) Parallel-distributed processing in olfactory cortex: new insights from morphological and physiological analysis of neuronal circuitry. Chem Senses 26:551-576. CrossRef Medline

Haberly LB, Price JL (1978) Association and commissural fiber systems of the olfactory cortex of the rat. II. Systems originating in the olfactory peduncle. J Comp Neurol 181:781-807. CrossRef Medline

Inui T, Shimura T, Yamamoto T (2006) Effects of brain lesions on tastepotentiated odor aversion in rats. Behav Neurosci 120:590-599. CrossRef Medline

Iurilli G, Ghezzi D, Olcese U, Lassi G, Nazzaro C, Tonini R, Tucci V, Benfenati F, Medini P (2012) Sound-driven synaptic inhibition in primary visual cortex. Neuron 73:814-828. CrossRef Medline

Jadauji JB, Djordjevic J, Lundström JN, Pack CC (2012) Modulation of olfactory perception by visual cortex stimulation. J Neurosci 32:3095-3100. CrossRef Medline

Johnson DM, Illig KR, Behan M, Haberly LB (2000) New features of connectivity in piriform cortex visualized by intracellular injection of pyramidal cells suggest that "primary" olfactory cortex functions like "association" cortex in other sensory systems. J Neurosci 20:6974-6982. Medline

Katz DB, Simon SA, Nicolelis MA (2001) Dynamic and multimodal responses of gustatory cortical neurons in awake rats. J Neurosci 21:44784489. Medline

Kay LM, Laurent G (1999) Odor- and context-dependent modulation of mitral cell activity in behaving rats. Nat Neurosci 2:1003-1009. CrossRef Medline

Kayser C, Petkov CI, Logothetis NK (2008) Visual modulation of neurons in auditory cortex. Cereb Cortex 18:1560-1574. CrossRef Medline

Koontz WLG, Fukunaga K (1972) Nonparametric valley-seeking technique for cluster analysis. IEEE T Comput C 21:171-178. CrossRef

Krushel LA, van der Kooy D (1988) Visceral Cortex - Integration of the Mucosal Senses with Limbic Information in the Rat Agranular Insular Cortex. J Comp Neurol 270:39-54, 62-63. CrossRef Medline

Lakatos P, Chen CM, O'Connell MN, Mills A, Schroeder CE (2007) Neuronal oscillations and multisensory interaction in primary auditory cortex. Neuron 53:279-292. CrossRef Medline

Luskin MB, Price JL (1983) The topographic organization of associational fibers of the olfactory system in the rat, including centrifugal fibers to the olfactory bulb. J Comp Neurol 216:264-291. CrossRef Medline

Macrides F, Chorover SL (1972) Olfactory bulb units-activity correlated with inhalation cycles and odor quality. Science 175:84-87. CrossRef Medline
Maier JX, Chandrasekaran C, Ghazanfar AA (2008) Integration of bimodal looming signals through neuronal coherence in the temporal lobe. Curr Biol 18:963-968. CrossRef Medline

Maier JX, Di Luca M, Noppeney U (2011) Audiovisual asynchrony detection in human speech. J Exp Psychol Hum Percept Perform 37:245256. CrossRef Medline

Mair RG, Gesteland RC, Blank DL (1982) Changes in morphology and physiology of olfactory receptor cilia during development. Neuroscience 7:3091-3103. CrossRef Medline

Mak YE, Simmons KB, Gitelman DR, Small DM (2005) Taste and olfactory intensity perception changes following left insular stroke. Behav Neurosci 119:1693-1700. CrossRef Medline

Masaoka Y, Satoh H, Akai L, Homma I (2010) Expiration: the moment we experience retronasal olfaction in flavor. Neurosci Lett 473:92-96. CrossRef Medline

McDonald JJ, Teder-Sälejärvi WA, Di Russo F, Hillyard SA (2005) Neural basis of auditory-induced shifts in visual time-order perception. Nat Neurosci 8:1197-1202. CrossRef Medline

Meredith MA, Nemitz JW, Stein BE (1987) Determinants of multisensory integration in superior colliculus neurons. I. Temporal factors. J Neurosci 7:3215-3229. Medline

Miller SD, Erickson RP (1966) Odor of taste solutions. Physiol Behav 1:145-146.

Miura K, Mainen ZF, Uchida N (2012) Odor representations in olfactory cortex: distributed rate coding and decorrelated population activity. Neuron 74:1087-1098. CrossRef Medline

Nadi NS, Head R, Grillo M, Hempstead J, Grannot-Reisfeld N, Margolis FL (1981) Chemical deafferentation of the olfactory bulb: plasticity of the levels of tyrosine hydroxylase, dopamine and norepinephrine. Brain Res 213:365-377. CrossRef Medline

Noesselt T, Rieger JW, Schoenfeld MA, Kanowski M, Hinrichs H, Heinze HJ, Driver J (2007) Audiovisual temporal correspondence modulates human multisensory superior temporal sulcus plus primary sensory cortices. J Neurosci 27:11431-11441. CrossRef Medline

Ogawa Y (1998) Firing properties of olfactory bulb neurons during sniffing in rats. Physiol Behav 64:755-764. CrossRef Medline

Palmerino CC, Rusiniak KW, Garcia J (1980) Flavor-illness aversions: the peculiar roles of odor and taste in memory for poison. Science 208:753755. CrossRef Medline

Pesaran B, Pezaris JS, Sahani M, Mitra PP, Andersen RA (2002) Temporal structure in neuronal activity during working memory in macaque parietal cortex. Nat Neurosci 5:805-811. CrossRef Medline

Piette CE, Baez-Santiago MA, Reid EE, Katz DB, Moran A (2012) Inactivation of basolateral amygdala specifically eliminates palatabilityrelated information in cortical sensory responses. J Neurosci 32: 9981-9991. CrossRef Medline

Rennaker RL, Chen CF, Ruyle AM, Sloan AM, Wilson DA (2007) Spatial and temporal distribution of odorant-evoked activity in the piriform cortex. J Neurosci 27:1534-1542. CrossRef Medline

Rhinehart-Doty JA, Schumm J, Smith JC, Smith GP (1994) A non-taste cue of sucrose in short-term taste tests in rats. Chem Senses 19:425-431. CrossRef Medline

Rolls ET, Baylis LL (1994) Gustatory, olfactory, and visual convergence within the primate orbitofrontal cortex. J Neurosci 14:5437-5452. Medline

Rozin P (1982) "Taste-smell confusions" and the duality of the olfactory sense. Percept Psychophys 31:397-401. CrossRef Medline

Rusiniak KW, Hankins WG, Garcia J, Brett LP (1979) Flavor-illness aversions-potentiation of odor by taste in rats. Behav Neural Biol 25:1-17. CrossRef Medline

Schoenbaum G, Eichenbaum H (1995) Information coding in the rodent prefrontal cortex. 1. Single-neuron activity in orbitofrontal cortex compared with that in pyriform cortex. J Neurophysiol 74:733-750. Medline

Schroeder CE, Foxe JJ (2002) The timing and laminar profile of converging inputs to multisensory areas of the macaque neocortex. Brain Res Cogn Brain Res 14:187-198. CrossRef Medline

Scott JW, McBride RL, Schneider SP (1980) The organization of projections from the olfactory-bulb to the piriform cortex and olfactory tubercle in the rat. J Comp Neurol 194:519-534. CrossRef Medline

Shi CJ, Cassell MD (1998) Cortical, thalamic, and amygdaloid connections of the anterior and posterior insular cortices. J Comp Neurol 399:440 468. CrossRef Medline 
Shusterman R, Smear MC, Koulakov AA, Rinberg D (2011) Precise olfactory responses tile the sniff cycle. Nat Neurosci 14:1039-1044. CrossRef Medline

Small DM, Voss J, Mak YE, Simmons KB, Parrish T, Gitelman D (2004) Experience-dependent neural integration of taste and smell in the human brain. J Neurophysiol 92:1892-1903. CrossRef Medline

Small DM, Gerber JC, Mak YE, Hummel T (2005) Differential neural responses evoked by orthonasal versus retronasal odorant perception in humans. Neuron 47:593-605. CrossRef Medline

Smith DV, Theodore RM (1984) Conditioned taste-aversions - generalization to taste mixtures. Physiol Behav 32:983-989. CrossRef Medline

Stein BE, Meredith MA (1993) The merging of the senses. Cambridge, MA: Massachusetts Institute of Technology.

Sugai T, Yoshimura H, Onoda N (2005) Functional reciprocal connections between olfactory and gustatory pathways. Chem Senses 30 [Suppl 1]: i166-i167. CrossRef

Travers JB, Norgren R (1986) Electromyographic analysis of the ingestion and rejection of sapid stimuli in the rat. Behav Neurosci 100:544555. CrossRef Medline

Van Buskirk RL, Erickson RP (1977) Odorant responses in taste neurons of the rat NTS. Brain Res 135:287-303. CrossRef Medline
Vassar R, Chao SK, Sitcheran R, Nuñez JM, Vosshall LB, Axel R (1994) Topographic organization of sensory projections to the olfactory bulb. Cell 79:981-991. CrossRef Medline

Veldhuizen MG, Nachtigal D, Teulings L, Gitelman DR, Small DM (2010) The insular taste cortex contributes to odor quality coding. Front Hum Neurosci 4.pii:58 CrossRef

Verhagen JV, Engelen L (2006) The neurocognitive bases of human multimodal food perception: sensory integration. Neurosci Biobehav Rev 30: 613-650. CrossRef Medline

Verhagen JV, Wesson DW, Netoff TI, White JA, Wachowiak M (2007) Sniffing controls an adaptive filter of sensory input to the olfactory bulb. Nat Neurosci 10:631-639. CrossRef Medline

Wesson DW, Wilson DA (2010) Smelling sounds: olfactory-auditory sensory convergence in the olfactory tubercle. J Neurosci 30:3013-3021. CrossRef Medline

Wilson DA, Sullivan RM (2011) Cortical processing of odor objects. Neuron 72:506-519. CrossRef Medline

Zukerman S, Touzani K, Margolskee RF, Sclafani A (2009) Role of olfaction in the conditioned sucrose preference of sweet-ageusic T1R3 knockout mice. Chem Senses 34:685-694. CrossRef Medline 